\title{
The mediating effect of cost leadership on the relationship between market penetration, market development, and firm performance.
}

\author{
Sidi Bello Alkasim \\ Umaru Ali Shinkafi Polytechnic, Sokoto, Nigeria \\ Haim Hilman \\ Abdul Manaf bin Bohari \\ Shahmir Sivaraj Abdullah \\ Mohd Rashdan Sallehddin \\ School of Business Management, \\ College of Business, Universiti Utara, Malaysia
}

\begin{abstract}
Keywords
Market penetration strategy, market development strategy, cost leadership strategy, SME performance.
\end{abstract}

\begin{abstract}
The main objective of this study is to examine strategic alignment and implementation perspective of manufacturing based of SMEs in Nigeria. The study established the strategic match between firm's growth strategy, competitive strategy, and performance. Specifically, this paper aims to investigate the effects of market penetration strategy, market development strategy and cost leadership strategy on performance. Hence, this study employed cross-sectional survey design; SPSS and PLS-SEM were used for preliminaries and hypothesis testing. 277 usable questionnaires were collected from owners-managers of manufacturing based of SMEs. The findings of this study indicate that market penetration strategy and market development strategy significantly influence the firm performance of manufacturing based SMEs in Nigeria. Also, the result shows that market penetration and market development strategy have a significant impact on cost leadership strategy, which enhances firm's competitiveness and competitive advantage. However, the result of mediating role of cost leadership strategy was established. The findings suggest that cost leadership strategy exert the relationship of market penetration $\mathcal{E}$ market development strategy and performance alignment. Therefore, owners-managers of manufacturing based of SMEs possibly make decisions considering their strategic orientation perspective collectively to integrate growth strategies and competitive strategy to sustain competitive advantage, improve competency and achieve superior performance.
\end{abstract}

Corresponding author: Sidi Bello Alkasim, Hilman Haim

Email addresses for corresponding author: alkasimsidi32@gmail.com, hilman@uum.edu.my

First submission received: $27^{\text {th }}$ July 2017

Revised submission received: $12^{\text {th }}$ October 2017

Accepted: $2^{\text {nd }}$ November 2017

\section{Introduction}

It has been recognized and documented the role played by Small and Medium Enterprises (SMEs) toward economic growth and social development to both developed and developing economies (SMEDAN, 2012; UNIDO, 2016). UNIDO and SMEDAN acknowledged that in most countries SMEs represents the larger share of the businesses operating and generates most of the job opportunities, which account for about two-thirds of the private businesses operating in a country. For instance, in the European countries, SMEs represent about $99 \%$ of all private business operating and creating most of the job opportunities (Airaksinen, Luomaranta, Alajääskö, \& Roodhuijzen, 2015).

Specifically, the manufacturing based SMEs is essential in creating youth innovation, improves export earning, increased raw material, boost capacity utilization, provides job opportunities and improve the gross domestic product (GDP) of the country (Abiodun, 2014;NBS \& SMEDAN, 2012). Thus, SMEs in developing countries are incapable of competing efficiently in both local market and international market (NBS \& SMEDAN, 2012). However, SMEs in such nations are struggling with the strategic orientation, 
access to market and marketing activities as a result of weak competition and high importation, of similar products (Uchegbulam, Akinyele, \& Ibidunni, 2015).

Recently, statistics have shown that the manufacturing based SMEs of Nigeria contributes only 5\% to the country's GDP in 2014 (FinIntell, 2014). However, the SMEDAN survey reports, indicated about $90 \%$ of SMEs cannot compete effectively in the local market, only $16 \%$ were able to access the other market segment across the country, while only $0.01 \%$ have access to the international market (NBS \& SMEDAN 2012).

Thus, the performance of SMEs in respect of their size solely depends on the owners-managers capability to integrate and build effective strategic decision that will transform the firm's competitiveness and enhance their competitive advantage over its rivals (Popa \& Soto-acosta 2015; Ojo \& Ololade 2013). These process of integrating, reconfiguring and building firm's strategies will help SMEs to improve their competence and enable them sustain competitive advantage, which in turn will help SMEs achieve superior performance, which is supported by dynamic capabilities view (Teece, 2007;Teece, Pisano, \& Shuen, 1997).

Therefore, growth level strategies are firm's managerial decisions (Hussain, Khattak, Rizwan, \& Latif, 2013), which reflects the firm's environment to offer better value for its' current and potential customers to strike a balance between the market requirements and the company's objectives (Basu \& Gupta, 2013). Previous studies have revealed empirical evidence of market penetration and market development as strategies that can offer firms with a competitive advantage over their competitors (Alkasim, Hilman, \& Manaf, 2017; Leitner, 2014; Hussain et al. 2013; Han, Dong, \& Dresner, 2013). Although, these strategies were examined in service sector, and were not directly studied on the firm's performance (Hussain et al. 2013). Uchegbulam et al. (2015) suggested that competitive strategy should mediate the relationship between SME's strategic choice and firm performance. Therefore, the purpose of this paper is to investigate the mediating effect of cost leadership on the relationship between market penetration, market development, and firm performance.

\subsection{Literature review and Hypothesis Development \\ 2.1 Performance}

For over many decades performance has been one of the major concern to different institutions; such as the academics, business organization, and governments (Tseng, Lan, Lu, \& Chen, 2013). Performance is measured to ascertain the quality of a firm's effectiveness (Prajogo \& Sohal, 2006). For instance, performance is measured in government to ascertain the success of policies, whereas in academics performance serves as an indicator to gauge the success of an institution, which acts as a strategy for an organization to practice. Therefore, performance has become more general and complex (Hudson, Smart, \& Bourne, 2001). Thus, the processes of performance have been discussed in the existing literature and believed to be significant in assessing the effectiveness of firm's performance (Kaplan \& Norton, 1996).

However, firm performance is created by firm's potential strategies to enable firms compete successfully in industry, which provides companies with higher performance on both financial and non-financial (Ferreira \& Otley, 2009). For a firm to achieve excellent performance, managers must develop strategies that will persistently provide them with a competitive advantage over their rivals and improve their competency (Stede, Wim, Chow, \& Lin, 2006). Thus, measuring the performance through market penetration \& market development and competitive strategy would serve as a source of competitiveness and enhance the competitive advantage of manufacturing based SMEs.

\subsection{Market penetration, Cost Leadership Strategies, and SME Performance.}

Market penetration is regarded as the first strategy of firm's growth, which is practice in almost every organization, so as to enhance sales volume, in the existing market for its current and new product (Hussain et al. 2013). According to Ansoff, MPS is a strategy that attempts to improve firm's sales without leaving the existing product in the current market with the aim to compete with the existing rivals products in the same market (Ansoff, 1965). Several researchers have discussed the impact of MPS techniques, as it enables the firm to increase the volume of sale, improve market share, repositioning their products, and create competitiveness (Uko \& Ayatse, 2014;Tavakolizadeh, 2014). Which in turn increase 
firm's competitive advantage and improve performance. Successful firm integrates their strategic orientation with competitive strategy in a competitive environment, to sustain their performance (Allen \& Helms, 2006; Mwangi \& Omhui, 2013).

However, MPS does not require any change in the product, what is needed is to focus on the techniques of selling the current products to existing markets to increase market share (Veraart, Thijsen, Tong, \& Leer, 2014), which in turn generate more revenue, competitive advantage and enhance their operational efficiency.

Therefore, in the light of the above, manufacturing-based SMEs in Nigeria can be found to be practicing market penetration techniques to increase their performance. Thus, this study hypothesized the following; H1: Market penetration strategy is significantly related to SME performance.

H2: Market penetration is significantly related to cost leadership strategy.

\subsection{Market Development, Cost Leadership Strategies and SME Performance.}

Market development is considered as the second firm's growth strategy. This strategy is used to inspire the organization to expand their opportunities and search for new customers (Tavakolizadeh 2014). MDS focus on enhancing firm's marketing strategy to increase the level of firm's income through product exploration (Hussain et al. 2013; Ansoff, 1965). By attracting new customers in an existing market with the current product, which will create more customers, brand equity and profitability (Veraart et al. 2014). For an organization to achieve competitiveness and improve competitive advantage, a firm must integrate its strategic orientation with cost efficiency (Porter, 1980, 1985), to sustain performance (Teece \& Pisano, 1994). Hence, this enables the firm to capture more customers in new and existing market. Cost efficiency can be obtain from product repackaging or product dimension, promotional tools and creating a new distribution system to enhance efficiency and effectiveness (Lechner \& Gudmundsson, 2014).

Barbero, Bueno, and Barringer, (2012) argued that for a firm to achieve effective competitiveness in a competitive market, marketing techniques must be improved and the firm must give emphasis on marketing techniques to improve their operations efficiency. Therefore, performance is improved when a firms' implements MDS in planning to capture new customers, thus, management must focus on internal efficiency, which requires utilization of firm's resource (Tavakolizadeh 2014). However, firms can explore their existing markets or discover potential needs of the current market segments (Barbero et al., 2012). Firm's MDS can increase the current level of sales, market share, competitiveness, competitive advantage, and sustain performance. Therefore, based on above argument, the study hypothesized the following:

H3: Market development is significantly related to SME performance.

H4: Market development is significantly related to cost leadership strategy.

\subsection{Cost Leadership as a Mediator}

Cost leadership is described as a strategy that a firm focuses on gaining a competitive advantage by having lowest cost operation in an industry (Porter, 1980, 1985). Therefore, when cost is the primary concern, the firm always chooses for cost leadership strategy, hence, go for cost efficiency (Mwangi \& Omhui, 2013). However, the ability to respond quickly and profitably to customer and market demands is critical to succeed in the today's competitive environment. Thus, firms must integrate its resources and capabilities to produce goods and services at lower cost with different features, which will enable them to sale their products at affordable and competitive price to customers. All of which will help improve competitiveness, competitive advantage and enhance performance (Teeratansirikool et al. 2013).

Previous studies examined the empirical evidence on the relationship between competitive strategy and performance (Hilman \& Kaliappen, 2014;Uchegbulam et al., 2015;Akingbade, 2014; Furrer, Sudharshan, Thomas, \& Alexandre, 2008) and supply chain strategy (Soni \& Kodali, 2011). The survival and growth of SMEs (Armstrong, 2013), the moderating effect of competitive strategy (Oltra \& Flor, 2010). However, there are few studies that established the mediating effect of cost leadership strategy (SantosVijande, Lopez-Sanchez, \& Trespalacios, 2012;Lechner \& Gudmundsson, 2014). Cost leadership may explain fully the relationship between growth strategy and performance of SMEs. Thus, based on the identified gap this study hypothesized the following;

H5: Cost leadership mediates the relationship between market penetration and performance 
H6: Cost leadership mediates the relationship between market development and performance.

\subsection{Research Framework}

The study illustrated the framework based on strategic orientation and implementation perspective that is considered to enable manufacturing based of SMEs in developing economies to integrate, reconfigure and rebuild firm's strategies to improve competency and achieve competitiveness and sustain performance (Teece \& Pisano, 1994; Teece et al., 1997). The framework highlighted two independent variables (market penetration \& market development strategy) that influence firm's product market growth, mediating variable (cost leadership strategy) competitiveness and competitive advantage towards sustaining dependent variable (firm performance). Below illustrates the mediating effect of cost leadership on the relationship between market penetration strategy \& market development strategy, and SME performance.

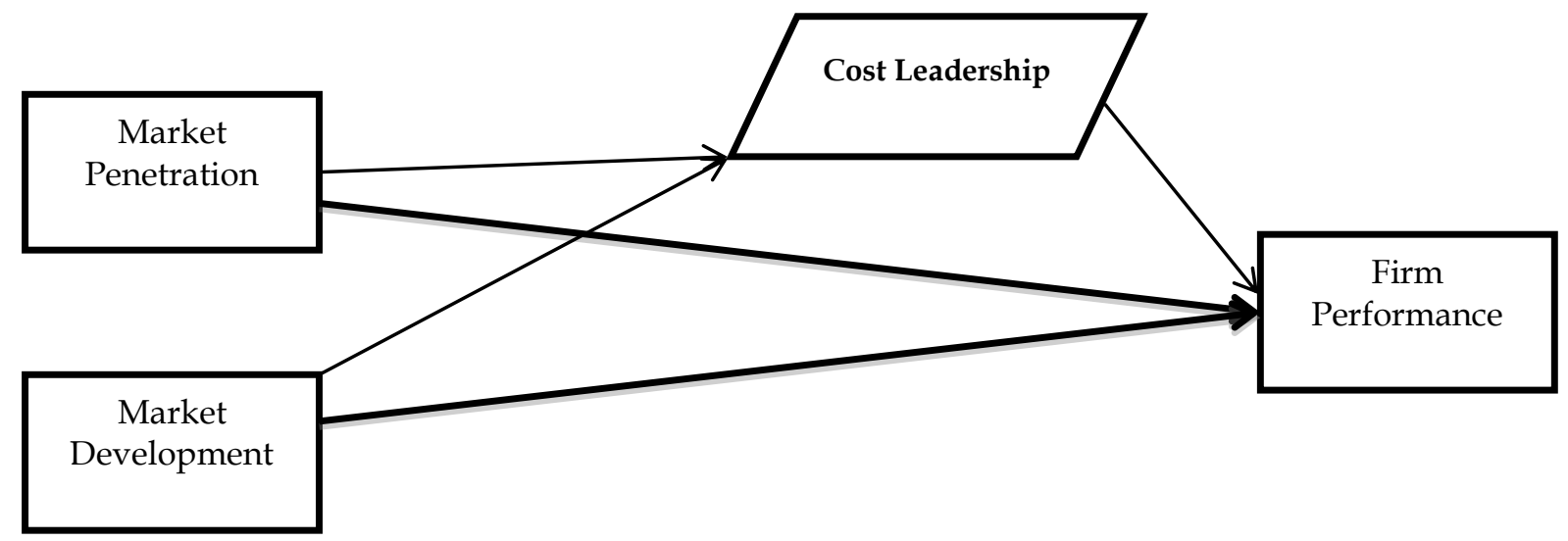

Figure 1.1: Research framework

\subsection{Methodology}

\subsection{Sample and data collection}

The population of this study was manufacturing based SMEs in North West of Nigeria, which consists of 1,814 SMEs. About 1,420 (78\%) of the SMEs located in three states. Base on the number of manufacturing based SMEs located in these states, statistics have revealed the rates of unemployment in the country is overwhelmed by the region (NBS Abstract Report, 2012) Therefore, 302 SMEs are the sample of this study (Dillman, 2007;Sekaran \& Bougie, 2013). To avoid any non-response issue and sample size error, the sample was increased to 453 (Bartlett et al. 2001). Thus, 329 questionnaires representing $(73 \%)$ response rates were collected from SMEs. Rejecting 26 questionnaires after found to be filled wrongly. Total of 303 questionnaires representing $(67 \%)$, were left for data cleaning and screening. SPPSS V23 was used for the preliminaries. A sample of 277 represents $(61 \%)$ cases valid, were used for further analysis.

\subsection{Results}

\subsection{Measurement model Analyses}

The study attempts to ascertain the construct validity, which the study followed two-step modeling approach as suggested by (J. Henseler, Ringle, \& Sinkovics, 2009). It started by measuring the convergent validity and reliability, pursued to discriminant validity. The table below presents the internal consistency and reliability. Based on the rule of thumb, the construct validity to ascertain if the loadings are within the range 0.4 to 0.7 ; composite reliability should be greater than 0.7 ; average variance extracted is greater than 0.5 (Hair, Hult, Ringle, \& Sarstedt, 2014).

Thus, 3 MPS, 2 MDS, 3 CLS, and 6 FPM were deleted because of their low loadings to meet the threshold of CR and AVE 0.7 and above and 0.50 and above respectively as recommended by (Hair et al., 2014). Therefore, in this study CR value, as the table above shows, the value of the constructs range 0.75 to 0.83 , which indicates the reliability of the measurement model. However, the result indicates AVE values range from 0.50 to 0.55 , which concludes the convergent validity is established. 


\begin{tabular}{lllll}
\hline Constructs & Items & Loadings & CR & AVE \\
\hline \multirow{3}{*}{ Market Penetration } & MP_3 & 0.580 & 0.750 & 0.500 \\
& MP_4 & 0.760 & & \\
MP_6 & 0.760 & & \\
Market Development & MD_1 & 0.790 & 0.820 & 0.530 \\
& MD_2 & 0.710 & & \\
Cost Leadership & MD_3 & 0.620 & & \\
& MD_4 & 0.770 & & \\
& CL_1 & 0.710 & & \\
Firm Performance & CL_2 & 0.780 & & \\
& CL_4 & 0.640 & & \\
& FP_1 & 0.82 & & \\
\end{tabular}

Table 1.Result of Measurement Model

Discriminant validity was considered to determine the extent to one construct is entirely different from each other construct (Hair et al., 2014). (Henseler, Ringle, \& Sarstedt, 2014) suggested the heterotriait-monotraitt ratio of correlation (HTMT). The study also tested the discriminant validity by comparing the square root of the AVE for each construct with the correlation presented in the correlation matrix. Table 2 below presents the results of the Fornell-Lerckert. Further, the result is supported by the result of HTMT assessment in Table 3, such that discriminant validity is established with $\mathrm{HTMT}_{0.90}$.

\begin{tabular}{lllll}
\hline Constructs & $\mathbf{1}$ & $\mathbf{2}$ & 3 & 4 \\
\hline Market Penetration & 0.710 & & & \\
Market Development & 0.520 & 0.730 & & \\
Cost Leadership & 0.290 & 0.440 & 0.710 & \\
Firm Performance & 0.500 & 0.510 & 0.260 & 0.740 \\
\hline
\end{tabular}

Table 2.Discriminant validity (Fornell-Larkert)

\begin{tabular}{lllll}
\hline Constructs & $\mathbf{1}$ & $\mathbf{2}$ & 3 & 4 \\
\hline Market Penetration & & & & \\
Market Development & 0.850 & & & \\
Cost Leadership & 0.520 & 0.700 & & \\
Firm Performance & 0.830 & 0.690 & 0.420 & \\
\hline
\end{tabular}

\subsubsection{Hypothesis Testing}

Table 3.Discriminant validity (HTMT)

This study examines the relationship between MPS and MDS on the firm performance of manufacturing based SMEs in Nigeria. The interpretation of the hypotheses analysis is summarized in Table 4 . The H1 indicates that MPS has a significant positive effect on firm performance, the result indicates $(\beta=0.32 ; \mathrm{t}=5.67, \mathrm{p}>0.01)$. Thus, $\mathrm{H} 1$ is supported. The finding is consistent with the previous studies of Han et al. (2013) and Hussain et al. (2013). Also, the H2 reveals that there is a significant positive influence of MDS on the firm performance, the result indicates $(\beta=0.35 ; t=6.15, p>0.01)$ and the result of this study is consistent with the findings of Hussain et al. (2013) and Leitner (2014). Therefore, the hypothesis $\mathrm{H} 2$ is supported. The study also tested direct hypotheses between exogenous constructs (MPS \& MDS) and the cost leadership strategy. The result indicates that H3; MPS significantly influence cost leadership $(\beta=0.12 ; t=1.97, p>0.05)$, H3: is supported. For H4 MDS significantly impact CLS ( $\beta=0.38$; 
$\mathrm{t}=6.39, \mathrm{p}>0.01$ ), H4 is supported, this result is consistent with the finding of previous studies (SantosVijande et al., 2012). All the direct hypotheses are supported.

\begin{tabular}{|c|c|c|c|c|c|}
\hline \multirow[t]{2}{*}{ Hypo } & \multirow[b]{2}{*}{ Relationship (Direct) } & \multicolumn{3}{|c|}{ STD } & \multirow[b]{2}{*}{ Decision } \\
\hline & & Beta & Error & T Value & \\
\hline H1 & Market Penetration ->Firm Performance & 0.320 & 0.056 & $5.757^{* * *}$ & Supported \\
\hline $\mathrm{H} 2$ & Market Development ->Firm Performance & 0.349 & 0.056 & $6.240^{* * *}$ & Supported \\
\hline H3 & Market Penetration ->Cost Leadership & 0.120 & 0.060 & $1.970^{* *}$ & Supported \\
\hline H4 & Market Development ->Cost Leadership & 0.380 & 0.060 & $6.390^{* * *}$ & Supported \\
\hline
\end{tabular}

Table 4.Structural Model (Hypotheses)

Concerning the hypotheses H5 \& H6 for (indirect effect) mediating effect of CLS on the relationship between MPS, MDS and firm performance. The results of the H5 indicate $(\beta=0.002, t=0.317$, NS) the hypothesis has a positive link, but not significant. Similarly, H6 the result indicates $(\beta=0.009, \mathrm{t}=$ 0.408 , NS) the hypothesis has a positive link, but not significant, this result is consistent with the findings of (Santos-Vijande et al., 2012; Lechner \& Gudmundsson 2014). Thus, the results of H5 and H6 establish a relationship, but not supported.

\begin{tabular}{lccccc}
\hline Hypo. & Indirect Relationship & $\begin{array}{c}\text { Beta } \\
\mathbf{a}^{*} \mathbf{b}\end{array}$ & STD Error & T Value & Decision \\
\hline H5 & MP ->CL ${ }^{*}$ CL->FPM & 0.002 & 0.007 & 0.317 & Not Supported \\
H6 & MD->CL*CL-> FPM & 0.009 & 0.024 & 0.408 & Not Supported \\
\hline
\end{tabular}

Table 5.Structural Model Bootstrapping (Mediating Effect)

The study assessed the effect size f2 to confirm the level of contribution for each construct on the main construct in the full model (R2 value) as recommended by Cohen, (1988). Inconsistent with the rule of thumb for f2, the effect size for the MPS has non-effect f2; MDS has small f2 of 0.141 on CLS (mediator). However, for dependent construct, MPS has an effect size f2 of 0.105, MDS has f2 of 0.103 considered to be small for respectively, whereas, CLS does not affect the main construct NA (see Table 6).

\begin{tabular}{lcccc}
\hline Effect Size & $\mathbf{R}^{2}$ Included & $\mathbf{R}^{2}$ Excluded & $f^{2}$ & Effect size \\
\hline Cost Leadership & 0.200 & & & \\
Market Penetration & & 0.195 & 0.006 & None \\
Market Development & & 0.087 & 0.141 & Small \\
Firm Performance & 0.332 & & & \\
Market Penetration & & 0.262 & 0.105 & Small \\
Market Development & & 0.263 & 0.103 & Small \\
Cost Leadership & & 0.339 & $\mathrm{~N} / \mathrm{A}$ & $\mathrm{N} / \mathrm{A}$ \\
\hline
\end{tabular}

Table 6.Total Effect Size f2 (Mediating Effect)

In this study, relevance was assessed to confirm the predictive relevance of the model (Henseler et al., 2009). Thus, the $\mathrm{Q}^{2}$ value was obtained based on stone-Geisser's test from PLS-SEM blindfolding, using cross-validated redundancy results for the endogenous latent constructs, the results indicate the $\mathrm{Q}^{2}$ value is greater than zero, which suggested the predictive relevance of the model (Henseler et al., 2009). See Table below.

\begin{tabular}{llll}
\hline Total & SSO & SSE & $Q^{2}$ (=1-SSE/SSO) \\
\hline Cost Leadership & 831 & 755.83 & 0.090 \\
Firm Performance & $1,108.00$ & 922.12 & 0.170 \\
\hline
\end{tabular}

\subsection{Discussions}

Table 7. Predictive Relevance Q2 (Mediating Effect) 
The result of this study confirms the impact of MDP, MDS and competitive strategy on the performance of manufacturing based SMEs in Nigeria. The findings of this study focused on the previous studies, which acknowledged the influence of firm's market penetration, market development, and cost leadership strategy. Strategic alignment is a source of competency that facilitates enterprises in developing competitive business environment (Hilman \& Kaliappen, 2014; Hussain et al., 2013; Lechner \& Gudmundsson, 2014; Uko \& Ayatse, 2014; Mwangi \& Omhui, 2013). The present study found that $61 \%$ of manufacturing based of SMEs in Nigeria recognized the importance of strategic alignment of firm's resources to enhance competitiveness and competitive advantage.

Hypotheses; $\mathrm{H} 1$ indicates that market penetration strategy has a significant impact on SME performance. The result shows that MPS was able to explain 32\% of manufacturing based on SME's performance. The result of this study is consistent with the previous studies such as (Hussain, et al., 2013; Han et al., 2013). H2 point out that $35 \%$ of MDS has more significant influence on SME performance. This result is reliable with the earlier studies (Hussain et al., 2013; Leitner, 2014). H3 as expected the result confirmed that MPS has a significant effect on CLS. Whereas, H4: MDS has more significant influence on CLS. The findings of this research could be as a result of the similarities in the functions of the strategies such as aggressive sales, increasing competitiveness, increase market share, cost efficiency, managing competitors and economies of scale (Santos-Vijande et al., 2012; Lechner \& Gudmundsson 2014).

Most surprisingly, the results of mediating effect of CLS for H5 \& H6: on the relationship between MPS, MDS, and firm performance. The condition of mediating effect was established, which indicates a significant positive association between MPS, MDS and CLS (Hayes \& Preacher, 2010). The model has delivered a strong indication on how these strategic factors are aligned together. The study revealed that cost leadership strategy has a limited or no impact in mediating the relationship of MPS, MDS and SME performance. The findings of this study indicate that MPS and MDS are strategic resources that enable firms to improve competitiveness and increase market share, and creates firm's efficiency and effectiveness when compared with competitors (Ansoff, 1965; Ansoff, 2002; Hussain et al., 2013). Thus, with CLS, manufacturing-based of SMEs that pursuing MPS, and or MDS might give a better performance.

\subsection{Conclusion, Implications, and Limitation}

The finding of this study has established empirical evidence for the manufacturing based on SMEs creating a strategic decision in determining growth strategy, competitive strategy and performance measurements. In struggling to create competitiveness, improve competitive advantage and enhance performance. Owners-managers of manufacturing based of SMEs may consider the current model and the findings of this study to align market penetration strategy, market development strategy and cost leadership strategy as a guide to reflect its strategic orientation in a competitive environment. In essence, the results of this study recommended that firm's strategic growth and competitive strategy would help manufacturing based SME's strategically, concerning integration and rebuilding of its strategies to create a sustainable competitive advantage and enhance performance.

Finally, the study is limited to the manufacturing based SMEs in Northwest in Nigeria. Also, this study examined only two growth level strategies, as well as only one competitive strategy. The present study employed cross-sectional research design. With regards to the source of data, only one source was used in gathering data from the owners-managers of manufacturing based SMEs in Nigeria. However, the present study suggested that future studies should consider the limitations as mentioned above, to provide a more comprehensive result and validate the current findings.

\section{Reference}

Abiodun, A. (2014). SME firms performance in Nigeria: Competitive advantage and its impact. International Journal of Research Studies in Management, 3(2), 75-86.

Airaksinen, A., Luomaranta, H., Alajääskö, P., \& Roodhuijzen, A. (2015). Statistics on small and mediumsized enterprises. Eurostat, (September), 1-14. Retrieved from

http://ec.europa.eu/eurostat/statistics-explained/index.php/Statistics_on_small_and_mediumsized_enterprises

Akingbade, W. A. (2014). Competitive strategies and improved performance of selected Nigeria 
telecommunication companies. Journal of Entrepreneurship Management and Innovation, 10(4), 143168.

Alkasim, Sidi, B., Hilman, H., \& Manaf, A. (2017). The effect of strategic growth on the performance of manufacturing based SME in Nigeria. International Journal of Research in Management, 4(7), 102-110.

Allen, R. S., \& Helms, M. M. (2006). Linking strategic practices and organizational performance to porter's generic strategies. Business Process Management, 12(4), 433-454.

Ansoff, I. (1965). Corporate Strategy. Management (Vol. 44).

Ansoff, I. Ansoff' s Matrix, CIMA 133-151 (2002).

Armstrong, C. E. (2013). Competence of flexibility? Survival and growth implications of competitive strategy preferences among small US businesses. Journal of Strategy and Management, 6(4), 377-398.

Barbero, N. J. L., Bueno, J. C. C., \& Barringer, B. (2012). Forms of growth: How SMEs combine forms of growth to achieve high growth. Journal of Management and Organization, 18(1), 81-97. http:/ / doi.org/10.5172/jmo.2012.18.1.81

Basu, S., \& Gupta, R. (2013). Explorations of strategic orientation ( SO ) dimensions on small firm growth and the challenge of resources. European Journal of Business and Management, 5(20), 242-248.

Dillman, D. A. (2007). Mail and Internet surveys: The tailored design method (2nd ed.). New Jersey: John Wiley $\mathcal{E}$ Sons Inc.

Ferreira, A., \& Otley, D. (2009). The design and use of performance management systems: An extended framework for analysis. Management Accounting Research, 20(4), 263-282.

http:// doi.org/10.1016/j.mar.2009.07.003

FinIntell. (2014). Sectoral analysis of Nigeria' s economy.

Furrer, O., Sudharshan, D., Thomas, H. \&, \& Alexandre, M. T. (2008). Resource configurations, generic strategies, and firm performance exploring the parallels between reource-based and competitive strategy theories in a new industy. Journal of Strategy and Management, 1(1), 15-40.

http:// doi.org/10.1108/JFM-03-2013-0017

Hair, F. J., Hult, M. T., Ringle, M. C., \& Sarstedt, M. (2014). A primer on partial least squares structural equation modeling (PLS-SEM). Sage, Los Angeles. http:// doi.org/10.1017/CBO9781107415324.004

Han, C., Dong, Y., \& Dresner, M. (2013). Emerging market penetration, inventory supply, and financial performance. Production and Operations Management, 22(2), 335-347. http://doi.org/10.1111/j.19375956.2011.01311.x

Hayes, A. F., \& Preacher, K. J. (2010). Quantifying and testing indirect effects in simple mediation models when the constituent paths are nonlinear. Multivariate Behavioral Research, 45(4), 627-660. http://doi.org/10.1080/00273171.2010.498290

Henseler, J., Ringle, C. M., \& Sarstedt, M. (2014). A new criterion for assessing discriminant validity in variance-based structural equation modeling. Journal of the Academy of Marketing Science, 43(1), 115135. http://doi.org/10.1007/s11747-014-0403-8

Henseler, J., Ringle, C. M., \& Sinkovics, R. R. (2009). The use of partial least squares path modeling in international marketing. Advances in International Marketing, 20, 277-319.

http://doi.org/10.1016/0167-8116(92)90003-4

Hilman, H., \& Kaliappen, N. (2014). Do Cost Leadership Strategy and Process Innovation Influence the Performance of Malaysia Hotel Industry? Asian Social Science, 10(10), 134-141.

http://doi.org/10.5539/ass.v10n10p134

Hudson, M., Smart, A., \& Bourne, M. (2001). Theory and practice in SME performance measurement systems. International Journal of Operations \& Production Management, 21(8), 1096-1115.

Hussain, S., Khattak, J., Rizwan, A., \& Latif, M. (2013). ANSOFF matrix, environment, and growth- An interactive triangle. Management and Administrative Sciences Review, 2(2), 196-206. Retrieved from http://www.absronline.org/journals/index.php/masr/article/view/102

Kaplan, S. R., \& Norton, P. D. (1996). Using the balanced scorecard as a strategic management system. Harvard Business Review, 74, 75-85.

Lechner, C., \& Gudmundsson, S. V. (2014). Entrepreneurial orientation, firm strategy and small firm performance. International Small Business Journal, 32(1), 36-60.

http://doi.org/10.1177/0266242612455034 
Leitner, K. (2014). Strategy formation in the innovation and market domain: emergent or deliberate? Journal of Strategy and Management, 7(4), 354-375.

NBS Abstract Report. (2012). National bureau of statistics annual abstract of tatistics, Federal Republic of Nigeria.

NBS \& SMEDAN. (2012). Survey report on Micro, Samll and Medium Enterprises (MSMEs) in Nigeria. National MSME Collaborative Survey.

Oltra, M. J., \& Flor, M. L. (2010). The moderating effect of business strategy on the relationship between operations strategy and firms' results. International Journal of Operations \& Production Management, 30(6), 612-638.

Porter, M. E. (1980). Competitive atrategy: Techniques for Analyzing industries and competitors. Macmillan, New York.

Porter, M. E. (1985). Competitive advantage: Creating and sustaining superior performance. The Free Press, New York.

Prajogo, D. I., \& Sohal, A. S. (2006). The relationship between organization strategy, total quality management (TQM), and organization performance--the mediating role of TQM. European Journal of Operational Research, 168(1), 35-50. http://doi.org/10.1016/j.ejor.2004.03.033

Santos-Vijande, M. L., Lopez-Sanchez, J. A., \& Trespalacios, J. A. (2012). How organizational learning affects a firm's flexibility, competitive strategy, and performance. Journal of Business Research, 65(8), 1079-1089. http://doi.org/10.1016/j.jbusres.2011.09.002

Sekaran, U., \& Bougie, R. (2013). Research methods for business: A skill building approach 6 th ed. John Wiley $\mathcal{E}$ Son.

Soni, G., \& Kodali, R. (2011). The strategic fit between "competitive strategy" and "supply chain strategy" in Indian manufacturing industry: an empirical approach. Measuring Business Excellence, 15(2), 7089. http://doi.org/10.1108/13683041111131637

Stede, V. Der, Wim, A., Chow, C. W., \& Lin, T. W. (2006). Strategy, choice of performance measures, and performance. Behavioral Research in Accounting, 18(2002), 185-205.

http://doi.org/10.2308/bria.2006.18.1.185

Tavakolizadeh, S. (2014). Growth strategies in mature markets.

Teece, D. \& Pisano, G. (1994). The dynamic capabilities of firms: An introduction. Industrial and Corporate Change, 3(3), 537-556.

Teece, D. (2007). Explicating dynamic capabilities: The nature and microfoundations of (sustainable) enterprise performance. Strategic Management Journal, 28, 1319-1350.

Teece, D., Pisano, G., \& Shuen, A. (1997). Dynamic capabilities and strategic management. Strategic Management Journal, 18(7), 509-533.

Tseng, K.-A., Lan, Y.-W., Lu, H.-C., \& Chen, P.-Y. (2013). Mediation of strategy on intellectual capital and performance. Management Decision, 51(7), 1488-1509. http://doi.org/10.1108/MD-03-2012-0143

Uchegbulam, P., Akinyele, S., \& Ibidunni, A. (2015). Competitive strategy and performance of selected SMEs in Nigeria. In International Conference on African Development Issues: Social and Economic Models for Development Track (pp. 326-333).

Uko, J. P., \& Ayatse, F. a. (2014). Market penetration as a growth strategy for small and medium-sized enterprises in Nigeria. Management and Administrative Sciences Review, 23(January), 8-23.

UNIDO. (2016). Industrial Development Report 2016: The Role of Technology and Innovation in Inclusive and Sustainable Industrial Development.

Veraart, D., Thijsen, T., Tong, T., \& Leer, J. van. (2014). Ansoff model: product/market expansion grid.

W. Mwangi, A., \& Omhui, K. (2013). Effects of Competitive Strategies on the Performance of Mission Hospitals in Kenya (A Case of Kijabe Mission Hospital). International Journal of Science and Research, 2(11), 14-19. 


\section{Appendixes}

Measuremen Model and Structural Model Figures
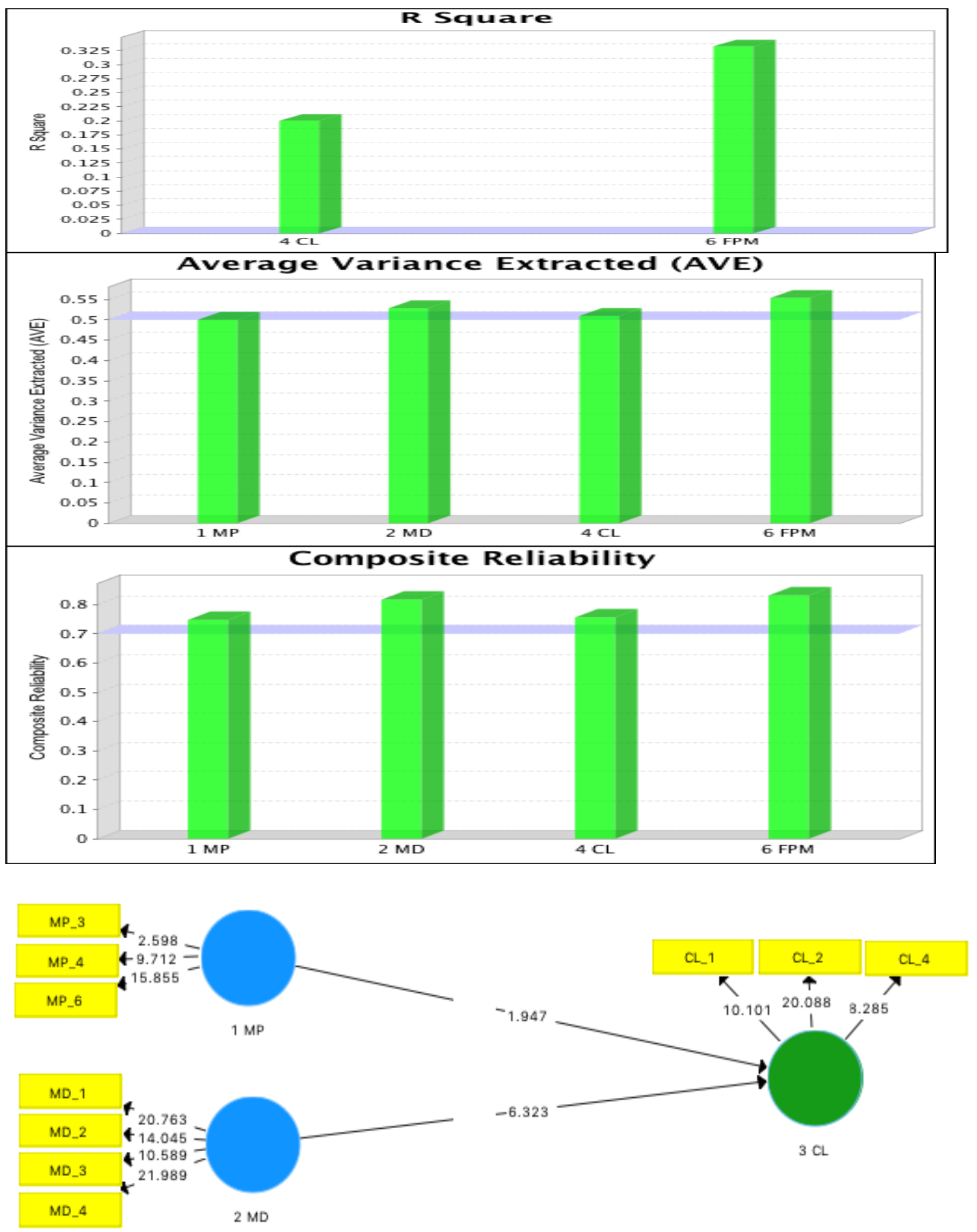

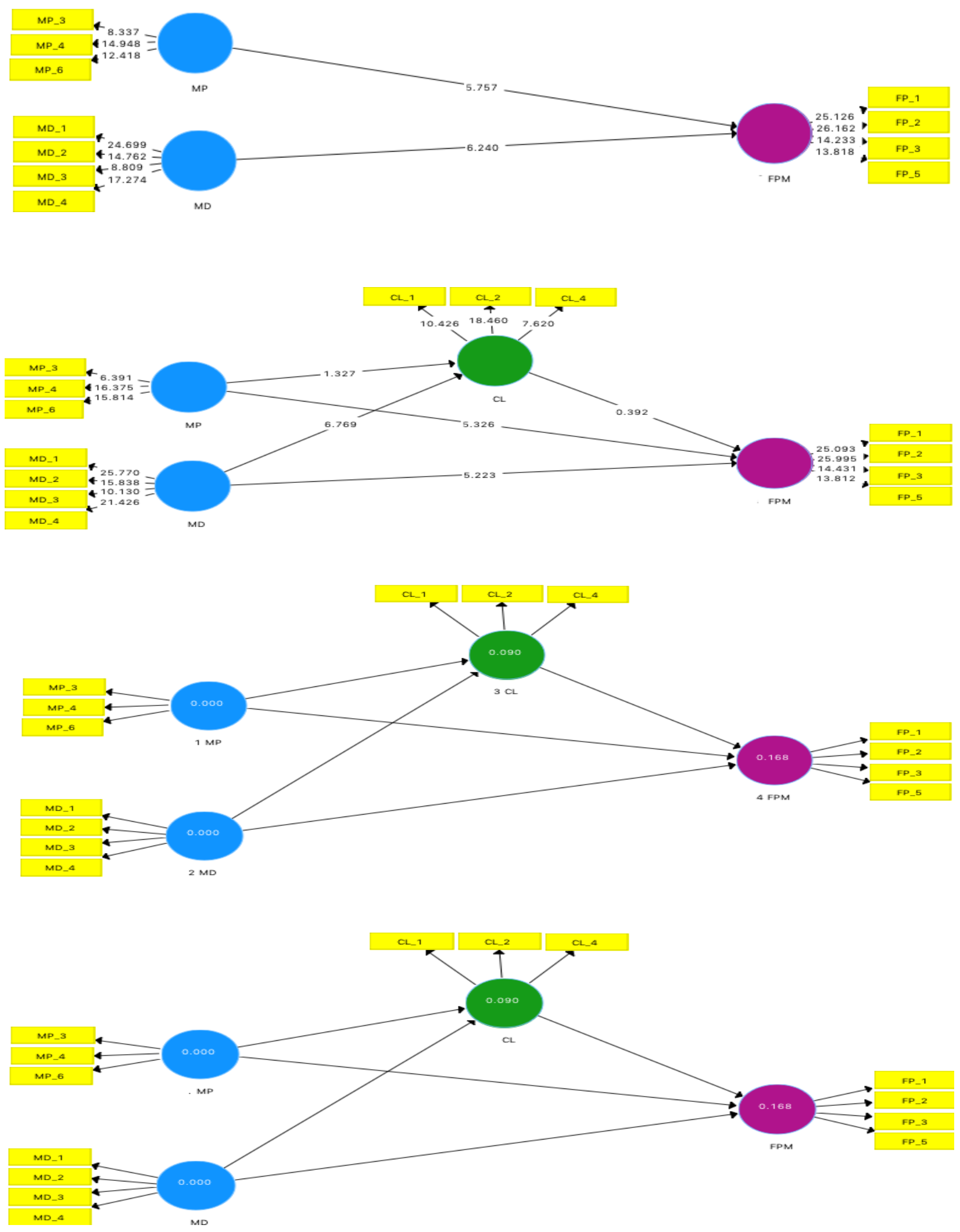